\title{
Elimination of mouse tumor cells from neonate spermatogonial cells utilizing cisplatin-entrapped folic acid-conjugated poly(lactic-co-glycolic acid) nanoparticles in vitro
}

This article was published in the following Dove Press journal:

International Journal of Nanomedicine

\begin{abstract}
Ronak Shabani, ${ }^{1,2}$ Mohsen
Ashjari, ${ }^{3}$ Khadijeh Ashtari, ${ }^{1,4}$

Fariborz Izadyar, ${ }^{5}$ Babak

Behnam, 1,6,7 Samideh

Khoei, ${ }^{8}$ Mohamad Asghari-

Jafarabadi, ${ }^{9}$ Morteza

Koruji ${ }^{1,2}$

'Cellular and Molecular Research Center, Iran University of Medical Sciences, Tehran, Iran; ${ }^{2}$ Department of Anatomical Sciences, School of Medicine, Iran University of Medical Sciences, Tehran, Iran; ${ }^{3}$ Department of Chemical Engineering, Faculty of Engineering, University of Kashan, Kashan, Iran; ${ }^{4}$ Department of Medical Nanotechnology and Faculty of Advanced Technology in Medicine, Iran University of Medical Sciences, Tehran, Iran; ${ }^{5}$ Prime Gen Biotech LLC, Santa Ana, CA, USA; ${ }^{6}$ Department of Medical Genetics and Molecular Biology, School of Medicine, Iran University of Medical Sciences, Tehran, Iran; ${ }^{7} \mathrm{NIH}$ Undiagnosed Diseases Program, Common Fund, NHGRI, National Institutes of Health, Bethesda, MD, USA; ${ }^{8}$ Department of Medical Physics, School of Medicine, Iran University of Medical Sciences, Tehran, Iran; ${ }^{9}$ Road Traffic Injury Research Center, Tabriz University of Medical Sciences, Tabriz, Iran
\end{abstract}

Correspondence: Morteza Koruji Department of Anatomical Sciences, School of Medicine, Iran University of Medical Sciences, Hemmat Highway, PO Box I4I55-5983, Tehran, Iran

Tel/fax +98 2I 88622689

Email koruji.m@iums.ac.ir
Background: Some male survivors of childhood cancer are suffering from azoospermia. In addition, spermatogonial stem cells (SSCs) are necessary for the improvement of spermatogenesis subsequent to exposure to cytotoxic agents such as cisplatin.

Objective: The aim of this study was to evaluate the anticancer activity of cisplatin-loaded folic acid-conjugated poly(lactic-co-glycolic acid) (PLGA) nanoparticles (NPs) on mouse malignant cell line (EL4) and SSCs in vitro.

Methods: SSCs were co-cultured with mouse malignant cell line (EL4) cells and divided into four culture groups: 1) control (cells were co-cultured in the culture medium), 2) co-cultured cells were treated with cisplatin $(10 \mu \mathrm{g} / \mathrm{mL}), 3)$ co-cultured cells were treated with cisplatin-loaded folic acid-conjugated PLGA NPs, and 4) co-cultures were treated with folic acid-conjugated PLGA for 48 hours. The NPs were prepared, characterized, and targeted with folate. In vitro release characteristics, loading efficiency, and scanning electron microscopy and transmission electron microscopy images were studied. Cancer cells were assayed after treatment using flow cytometry and TUNEL assay. The co-cultures of SSCs and EL4 cells were injected into seminiferous tubules of the testes after treating with cis-diaminedichloroplatinum/PLGA NPs.

Results: The mean diameter of PLGA NPs ranged between 150 and $250 \mathrm{~nm}$. The number of TUNEL-positive cells increased, and the expression of Bax and caspase-3 were upregulated in EL4 cells in Group 4 compared with Group 2. There was no pathological tumor in testes after transplantation with treated co-cultured cells.

Conclusion: The PLGA NPs appeared to act as a promising carrier for cisplatin administration, which was consistent with a higher activation of apoptosis than free drug.

Keywords: spermatogonial cells, cancer cells, cisplatin, PLGA nanoparticles, drug delivery, folic acid

\section{Introduction}

Cancer is a disease distinguished by the uncontrolled growth and spread of abnormal cells and is still the second most common cause of death worldwide. Current treatment for cancer involves surgery, radiation, hormone therapy, and chemotherapy. ${ }^{1}$ The most frequent types of testicular cancer in the prepubertal age are pure teratomas and yolk sac tumors. ${ }^{2}$ In addition, acute lymphoblastic leukemia is detected in $34 \%$ of cancerous patients aged from 0 to 14 years. ${ }^{3}$ Spermatogenesis and male fertility are affected by whole-body radiation, radiation to the gonads, and alkylating chemotherapies because of their toxicity. ${ }^{4}$ One late effect of childhood cancer therapy is infertility which is seen in 
$15 \%-48 \%$ of male survivors. Sperm banking is an option for adult men before initiating treatment, but it cannot be used to preserve the fertility of prepubertal boys who do not have any sperm. This is a real health concern for males, while event-free survival rate of children with cancer is nearly $85 \% .^{5}$ Therefore, these patients can expect to have a normal productive life after treatment. There are hopeful stem cell research technologies (eg, spermatogonial stem cells [SSCs] transplantation), ${ }^{6-9}$ testicular tissue grafting, testicular organ culture, and in vitro derivation of haploid gametes ${ }^{10}$ which are effective fertility options for these patients. Decontamination of preserved testicular tissue is a huge concern in cancer patients, as testicular biopsy in these patients could save the testicle tissues from malignant cells. Transplantation of leukemic cells alone or in SSC suspensions was found to impel shift of leukemia in the previous studies. ${ }^{11,12}$ Therefore, isolation of germ cells from malignant cells should be accomplished. Previous studies have shown that fluorescent-activated cell sorting (FACS)or magnetic-activated cell sorting (MACS)-based methods can decontaminate malignant cells from heterogeneous testicular cell suspensions. ${ }^{12-18}$ However, decontamination of malignant cells by the abovementioned methods does not seem to be sufficient. Meanwhile, using a further method is necessary because even low levels of contamination can induce malignancy. ${ }^{11,12,19}$ Cisplatin is an important chemotherapeutic agent that is noted for its activity against testicular germ cell cancers. Cisplatin forms intra- and interstrand DNA cross-links, so it was suggested early that damage to DNA might be responsible for the therapeutic efficacy of cisplatin. ${ }^{20}$ However, there are severe side effects, particularly renal toxicity, associated with the usage of cisplatin. ${ }^{21}$ Conventional chemotherapy is highly nonspecific in targeting the drug to tumoral cells due to simultaneous exposure of the chemotherapeutic agent to normal and cancerous cells. Therefore, no maximum dose of the drug is allowable for the treatment of tumoral cells. ${ }^{22}$ We have shown earlier that treatment with optimal and effective doses of cisplatin can be useful in the isolation of SSCs from tumoral cells. ${ }^{23}$ One of the further methods for the decontamination of cancerous cells from testicular cell suspensions can be used for smart drug delivery. Nanoparticles (NPs) are used as drug delivery vectors for targeting large doses of chemotherapeutic drugs or therapeutic genes into malignant cells, but they have a rare effect on healthy cells. ${ }^{22}$ Internalization of NPs into the cancer cells is enhanced due to positively charged surfaces and longer circulation times. Meanwhile, hydrophilic surfaces have modified enhancement of drug delivery to cancerous cells. ${ }^{24}$
Poly(lactic-co-glycolic acid) (PLGA) is one of the NP systems that can be used for cancer therapeutics due to its biocompatibility and biodegradability. In fact, PLGA undergoes hydrolysis in the body to produce the biodegradable metabolite monomers, lactic acid and glycolic acid, thus resulting in a minimal systemic toxicity. ${ }^{25}$ PLGA is approved by the US Food and Drug Administration (FDA) and European Medicines Agency (EMA) for use in different drug delivery systems in humans. ${ }^{26}$ Furthermore, the therapeutic efficacy of drug-loaded NPs is increased by targeted tumor-specific strategy. In this regard, folate receptor (FR) induction is one of the most hopeful strategies for smart targeting, and extensively utilized for drug targeting in epithelial cancers. ${ }^{27}$ Folate-conjugated nanocarriers have a high affinity and internalize into the cells via receptormediated endocytosis. Furthermore, normal cells are able to transfer folic acid alone in a reduced form such as 5-methyltetrahydrofolate, although they cannot transfer conjugated folate across their cell membrane. ${ }^{28}$ The influx of conjugated folates into the tumoral cells occurs mainly via the FRs, as these receptors are notably upregulated on cancerous cells compared with normal cells. ${ }^{29}$ Other advantages of folate/ PLGA are their high binding affinity, stability on storage and in circulation, and ease of conjugation to nanocarriers. ${ }^{28,30}$

For the potential clinical application of restoring fertility after anticancer therapy, and based on the promising data on sorting of SSCs from tumoral cells in previous reports, in this work we developed cisplatin-loaded folic acid-conjugated PLGA NPs to investigate elimination of EL4 cancer cells from SSCs, aiming to achieve a controlled inhibition of tumoral cell proliferation induced by drug delivery.

\section{Experimental section Materials}

Cisplatin (cis-platinum diammine dichloride), PLGA (Resomer RG502H) with a 50:50 mole ratio of glycolic acid to lactic acid and a molecular weight of 12,000 g/mol, polyvinyl alcohol (PVA; 89 mol\% hydrolyzed), Span 60 (s7010), and Tween 60 (p1629) were purchased from Sigma (St Louis, MO, USA).

\section{Animals}

In this experiment, 60 neonatal mice between 3 and 6 days old were used. These animals were obtained from the National Medical Research Institute (NMRI), originally taken from stocks of Razi Laboratory (Tehran, Iran). They were kept in cages made of plastic in a room at a temperature range of 
$22^{\circ} \mathrm{C}-25^{\circ} \mathrm{C}$, with a 12 -hour light/dark cycle. The research was approved by Research Ethics Committee of Iran University of Medical Sciences and was in accordance with the National Research Council guidelines (code: 21650).

\section{Co-culture of EL4 cells and SSCs}

EL4 cell line and neonatal mouse SSCs were prepared, and the cultures were initiated as described earlier. ${ }^{23}$ The mouse acute lymphoblastic leukemia cell line EL4 was provided by the culture collection of Pasteur Institute, Tehran, Iran, and the isolation of SSCs from mice in this research was performed after obtaining ethical approval.

The SSCs co-cultured with testicular cell suspensions were contaminated with $5 \%$ EL4 cells at $37^{\circ} \mathrm{C}$ in a $5 \% \mathrm{CO}_{2}$ atmosphere in DMEM/F12 medium (Gibco) supplemented with $2 \%$ fetal bovine serum, penicillin $(100 \mathrm{U} / \mathrm{mL})$, streptomycin $(100 \mu \mathrm{g} / \mathrm{mL})$, and gentamycin $(40 \mu \mathrm{g} / \mathrm{mL})$. In our previous study, the identity of the cultured cells was confirmed by the expression of specific markers (alpha-6-integrin and c-kit positive for SSCs and $\mathrm{H}-2 \mathrm{~Kb}$ positive for EL4 cells). In addition, functional transplantation assay for SSCs and tumorigenicity assays for EL4 cells were performed in recipient busulfan-treated testes.

\section{Experimental design}

In this study, EL4 and SSCs were classified into four groups as follows: Group 1 was control (received medium); Group 2 received blank NPs in the medium; Group 3 received an effective dose of cisplatin $(10 \mu \mathrm{g} / \mathrm{mL}) ;{ }^{23}$ and Group 4 received cisplatin-loaded folic acid-conjugated PLGA NPs.

\section{Preparation and characterization of cisplatin-loaded PLGA NPs}

Preparation of nanocapsule containing cisplatin was performed using a modified water/oil/water (W/O/W) double-emulsion solvent evaporation procedure, ${ }^{31}$ with some modification. Briefly, cisplatin and distilled water (DW) mixture was prepared by dissolving cisplatin in DW. This mixture was blended in dichloromethane (DCM) solution of the polymer (PLGA and Span 60) by ultrasonication for 45 seconds (power $50 \mathrm{~W}$ ) in an ice bath to obtain a water-in-oil emulsion. Then, this emulsion was proximately dispensed into a $12 \mathrm{~mL}$ aqueous solution of PVA $(2 \%, \mathrm{w} / \mathrm{v})$ containing Tween 60 , and the mixture was ultrasonicated again. The solvent exclusion of the final double emulsion (W/O/W) was carried out via vaporization, and complete dispersion was done through mechanical stirring. For vaporization, the resulting double emulsion was diluted in an aqueous solution of PVA under mechanical stirring for a period of 3 hours at room temperature to allow the evaporation of DCM. Finally, drug-loaded NPs were collected by centrifugation and washed three times with deionized water. The obtained nanocapsules were dried by freeze-drying and stored at $4^{\circ} \mathrm{C}$. Blank NPs were prepared by the method described above except for the addition of cisplatin.

\section{Surface functionalization of cisplatin- loaded PLGA NPs with folate}

In brief, folic acid was reacted with dicyclohexylcarbodiimide and $N$-hydroxysuccinimide (NHS) in DMSO with stirring. The activated folate was then reacted overnight with ethylene diamine in the presence of pyridine $(0.2 \mathrm{~mL})$ as a catalyst. The aminated folate $\left(\mathrm{Fol}-\mathrm{NH}_{2}\right)$ was precipitated out by adding excess of cold acetonitrile, followed by vacuum filtration. For conjugation of Fol- $\mathrm{NH}_{2}$ onto the surface of PLGA NPs, $10 \mathrm{mg}$ of cisplatin-loaded NPs was dispersed in $5 \mathrm{~mL}$ of phosphatebuffered saline (PBS; $0.02 \mathrm{M}, \mathrm{pH} 7.4$ ), followed by addition of ethyl(dimethylaminopropyl) carbodiimide (EDC) and NHS to the above suspension. EDC activation was carried out by agitating the above suspension for 2 hours at room temperature using a magnetic stirrer. The excess of unreacted EDC and NHS was removed, and activated NPs were recovered by ultracentrifugation. The activated NPs were dispersed in PBS (0.02 M, pH 7.4), followed by the addition of Fol- $\mathrm{NH}_{2}$ solution $(1 \mathrm{mg} / \mathrm{mL}$ in PBS $){ }^{32}$ The solution was again agitated at room temperature, and excess of unconjugated folate was removed by ultracentrifugation. The recovered folateconjugated NP suspension was lyophilized. Conjugation of folate onto PLGA NPs surface was confirmed by Fourier transform infrared spectroscopy (FTIR) analysis.

\section{Determination of loading efficiency and in vitro release rate of cisplatin}

Absorption measurements were performed to determine the amount of drug encapsulated in PLGA using UV-vis spectrophotometer (model UV-1650 PC; Shimadzu Europe, Tokyo, Japan). First, $5 \mathrm{mg}$ of the dry PLGA nanocapsules was dissolved in $1 \mathrm{~mL}$ DCM. Then, $1 \mathrm{~mL}$ of PBS (pH 7.4) was added. For precipitating polymer phase from aqueous phase, centrifugation was performed at 10,000 rpm for 20 min. The drug loading of this solution was determined by measuring the absorption peak at $300 \mathrm{~nm}$ with a UV-vis spectrophotometer, and quantitatively determined by comparison with a previously established standard curve. The concentration of cisplatin was investigated using Beer's 
law. The results of the experiment are expressed as the average of three different analyses.

Encapsulation efficiency, EE $(\%)=$

Amount of encapsulated cisplatin $(\mathrm{mg})$ in nanocapsule

Initial amount (mg) of

cisplatin used in the recipe

In addition, for determining the in vitro release of cisplatin from NPs, $5 \mathrm{mg}$ of nanocapsule powder was suspended in $5 \mathrm{~mL}$ of PBS (pH 7.4). The suspension was incubated at $37^{\circ} \mathrm{C}$. The tubes were centrifuged at definite time intervals. After centrifugation, the supernatants were collected for the determination of cisplatin, analyzed using the UV-vis spectrophotometer by measuring the absorption peak at $300 \mathrm{~nm}$, and replaced by the same quantity of fresh PBA solution. The tubes were then placed back in the incubator.

\section{Particle size analysis and zeta potential measurement}

The particle size of the nanocapsules was determined by dynamic light scattering (DLS) on a Nano-ZS system (Model ZEN3600; Malvern Instruments, Malvern, UK) using a zeta sizer. In brief, $1 \mathrm{mg} / \mathrm{mL}$ of NP suspension was prepared in MilliQ water, and sonicated for 30 seconds over an ice bath using a sonicator (with $50 \mathrm{~W}$ energy output) to avoid the formation of large aggregates. The zeta potential of the nanoformulations was determined by the same instrument, following the above protocol, before and after folate conjugation. All measurements were performed in triplicates.

\section{Transmission electron microscopy (TEM) and scanning electron microscopy (SEM)}

The NPs were evaluated for size by TEM (LEO 906; Carl Zeiss). After sonicating for $5 \mathrm{~min}$, one drop of NP suspension ( $1 \mathrm{mg} / \mathrm{mL}$ ) was placed on a carbon-coated copper TEM grid and dried in the open air before negative staining with uranyl acetate solution (1\%). Size and surface morphology of nanocapsules were investigated by SEM with Vega-II from Tescan Co. (Brno, Czech Republic). The samples for SEM analysis were put under vacuum and sputter-coated with gold.

\section{FTIR analysis}

The infrared spectra of cisplatin, PLGA, folic acid, and cisplatin-loaded folate-conjugated PLGA NPs were recorded using a Fourier transform infrared spectrophotometer (FTIR-ATR-Perkin Elmer 2000). The spectra of all the materials were recorded at a frequency range of $500-4,000 \mathrm{~cm}^{-1}$ and averaged over four runs. The powdered samples were placed on the attenuated total reflectance crystal, and then compressed using an axial screw.

\section{In vitro cellular cytotoxicity assay}

MTT assay was performed to evaluate the toxicity of blank NPs and cisplatin-loaded PLGA NPs and that of free cisplatin against EL4 cancer cells and SSCs separately. The cells $\left(5 \times 10^{3}\right.$ per well $)$ were seeded in 96 -well plates. After treating with various concentrations of NPs $(0.5,1$, and $2 \mathrm{mg} / \mathrm{mL})$ and $10 \mu \mathrm{g} / \mathrm{mL}$ free cisplatin for 48 hours, the culture medium was removed and $10 \mu \mathrm{L} /$ well MTT solution $(5 \mathrm{mg} / \mathrm{mL})$ was added, plates were incubated at $37^{\circ} \mathrm{C}$ for 3 hours, and then the medium was replaced with $100 \mu \mathrm{L}$ of DMSO to dissolve the formazan crystals. The absorbance was measured at $570 \mathrm{~nm}$ using a microplate reader. The experiments were performed three times.

\section{In situ cell death detection of EL4 cells following treatment}

EL4 cells (5,000 per well) were incubated with $10 \mu \mathrm{g} / \mathrm{mL}$ cisplatin and cisplatin-loaded PLGA NPs. After 48 hours of incubation, apoptosis was detected by TUNEL assay. TUNEL staining was carried out using an In-Situ Cell Death Detection Kit (Roche, Basel, Switzerland) according to the provided protocol.

\section{Determination of apoptotic and antiapoptotic gene expression following treatment by quantitative reverse transcription PCR (qRT-PCR)}

The effect of free cisplatin and cisplatin-loaded PLGA NPs on Bax, bcl2, and caspase-3 gene level in EL4 cells was investigated by real-time quantitative PCR analysis. Briefly, EL4 cells were incubated with $10 \mu \mathrm{g} / \mathrm{mL}$ concentrations of cisplatin and $2 \mathrm{mg} / \mathrm{mL}$ of NPs for 48 hours. Total mRNA was isolated, and real-time PCR amplification of cDNAs was performed following the protocol. The relative quantification of gene expression was performed using GAPDH as an internal control.

\section{Determination of cell percentage of SSCs and EL4 cells using flow cytometry after co-culture}

After co-culture of SSCs and EL4 cells with $10 \mu \mathrm{g} / \mathrm{mL}$ concentration of cisplatin, blank NPs, and cisplatin-loaded PLGA NPs for 48 hours, the cells were incubated with an FITC-conjugated mouse anti-H-2Kb monoclonal 
antibody (553569; Pharmingen) at 1:50 concentration and phycoerythrin-conjugated rat anti-CD49f monoclonal antibody (ab95703; Abcam, Cambridge, UK) (concentration of 1:10) for $20 \mathrm{~min}$ at $4^{\circ} \mathrm{C}$ in the dark.

\section{In vivo evaluation of decontamination of SSCs from EL4 cells after treatment}

After adding the cisplatin-loaded PLGA NPs to the cocultured cells, the mixture of cells was transferred to the recipient busulfan-treated NMRI mice's efferent ductuli ${ }^{33}$ (6-8 weeks, male, 20-30 g body weight) to evaluate the tumor efficacy. After 2 months, their abdomen was evaluated for the presence of tumors, and the testes were isolated and prepared for histological evaluation as described earlier. ${ }^{23}$

\section{Statistical analysis}

All quantitative data derived from this study were analyzed statistically and presented as mean $\pm \mathrm{SD}$. Statistical significance was determined using the one-way ANOVA test, followed by the post hoc Tukey's test. The cell percentages determined using flow cytometry were compared using an independent $t$-test. $P$-values less than 0.05 were considered significant.

\section{Results \\ Physiochemical characterization of cis-diaminedichloroplatinum (CDDP)/ PLGA NPs}

The release of cisplatin from the prepared nanocapsules was evaluated in a PBS release medium with a $\mathrm{pH}$ of 7.4 at $37^{\circ} \mathrm{C}$. The drug release was determined at definite intervals up to 7 days. The resulting curves exhibited a biphasic drug release pattern that was characterized by an initial rapid phase followed by a slower, continuous-release phase during 1 week (Figure 1A). The release of cisplatin from NPs was slightly faster in the first 48 hours; during this period, $70 \%$ of cisplatin was released. After 168 hours of incubation, about 97\% of cisplatin was released from the CDDP/PLGA NPs at $\mathrm{pH}$ 7.4. The loading efficiency of cisplatin was calculated from the amount of recovered cisplatin from each batch relative to the initial amount of cisplatin used in the preparation process, and it was found to be about $78 \% \pm 2.1 \%$. The release of drugs from folate-conjugated NPs almost mimicked the pattern of unconjugated NPs release (data not shown). DLS analysis revealed that the NPs had a mean hydrodynamic diameter of $235 \pm 7.3 \mathrm{~nm}$ with a polydispersity index of 0.585 and a negative zeta potential of -9 to $-14.5 \mathrm{mV}$ (Figure 1B). These negative values were due to the ionization of carboxyl groups on the surface of the nanocapsules. The surface modification of PLGA-NPs with folate had no significant effect on their size characteristics; however, zeta potential changed to $2.6 \pm 0.8 \mathrm{mV}$ which indicated the presence of folic acid. The conjugation of folate to PLGA NPs and loading of the drug were confirmed by FTIR analysis, and the peaks at 1,475 , 1,274 , and $1,170 \mathrm{~cm}^{-1}$ in folate-functionalized NPs clearly indicated the formation of amide bond following conjugation (Figure 1C). The small new peaks at 800 and $1,626 \mathrm{~cm}^{-1}$ seen in cisplatin-loaded NPs proved the presence of the drug in NPs.

\section{SEM and TEM observations}

The SEM images showed the outer surface of nanocapsules. It was obvious that the nanocapsules had a smooth surface and were sphere-shaped (Figure 1D). The micrographs obtained from the TEM analysis gave some information about the structure, internal morphology, particle size, and distribution of the nanocapsules. Figure 1E shows the TEM micrographs of the CCDP/PLGA sample, which illustrates the spherical structure of the nanocapsules with the particle size in the range of $150-250 \mathrm{~nm}$ and their sizes consistent with DLS results. Indeed, no aggregation of nanocapsules was found while they were discrete due to negative surface charge according to zeta potential results.

\section{Assessment of cytotoxicity of CDDP/ PLGA NPs, free cisplatin, and blank NPs on EL4 and SSCs}

The cytotoxicity of CDDP/PLGA NPs, free cisplatin, and blank NPs on SSCs and EL4 cell lines was investigated using MTT assays (Figure 2A-D). As shown in Figure 2C, both cell lines were treated with varying concentrations of $0.5,1$, and $2 \mathrm{mg} / \mathrm{mL}$ of CDDP/PLGA and blank NPs and $10 \mu \mathrm{g} / \mathrm{mL}$ of free cisplatin for 48 hours on the basis of a previous study (time and dose of drug). To determine the best effect of NPs on the elimination of tumoral cells, cell viability was evaluated 48 hours following exposure with free cisplatin. The EL4 survival rates were found to be about $37.57 \% \pm 0.55 \%, 32.79 \% \pm 0.39 \%$, and $25.42 \% \pm 0.36 \%$ at the concentrations of $0.5,1$, and $2 \mathrm{mg} / \mathrm{mL}$ of CDDP/PLGA NPs, respectively. However, SSCs survival rates were found to be about $78.50 \% \pm 1.34 \%, 71.34 \% \pm 0.46 \%$, and $60.74 \% \pm$ $0.44 \%$ at the concentrations of $0.5,1$, and $2 \mathrm{mg} / \mathrm{mL}$ of CDDP/ PLGA NPs, respectively. As shown in Figure 2C, the viabilities of EL4 cells and SSCs treated with $0.5,1$, and $2 \mathrm{mg} / \mathrm{mL}$ of blank NPs were similar to those of the control group (no significant difference) at all tested concentrations in 48 hours, revealing the low toxicity and biocompatibility of the copolymers to the cells. As shown in Figure 2D, $2 \mathrm{mg} / \mathrm{mL}$ concentration of CDDP/PLGA NPs and free cisplatin were compared to each of the cell lines. The EL4 $\mathrm{IC}_{50}$ and SSCs 

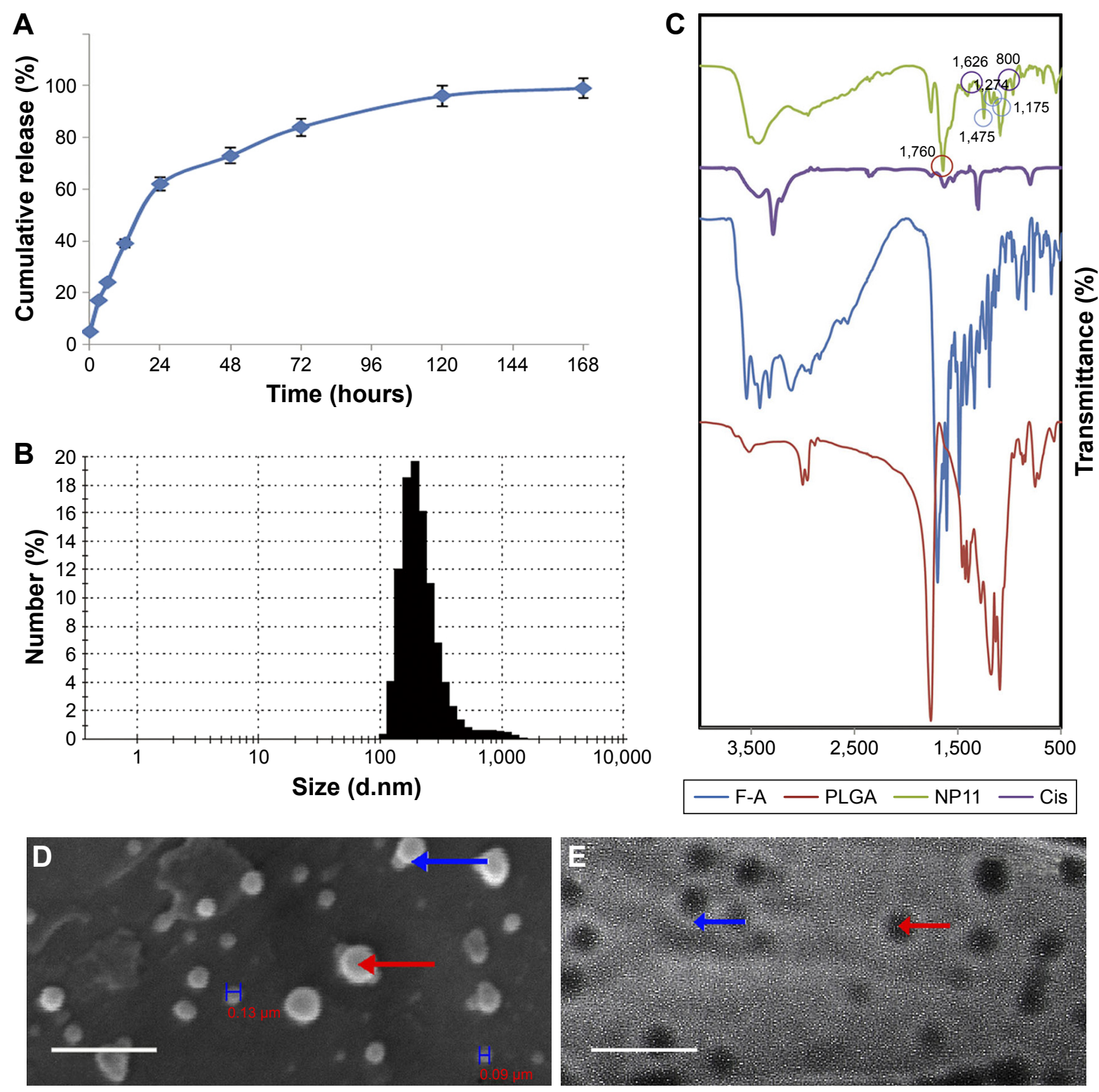

Figure I Physiochemical characterization and SEM and TEM analyses of CDDP/PLGA NPs.

Notes: (A) Sustain-release phenomenon exhibited by drug-loaded NPs in PBS with pH of 7.4 at $37^{\circ} \mathrm{C}$. Initially, $30 \%$ of cisplatin was released, and after 48 hours, $70 \%$ of cisplatin was released. The values are shown as mean $\pm S D, n=3$. (B) Size of NPs was measured by DLS. (C) FTIR spectrum of CDDP/PLGA NPs. (D) Scanning electron micrographs of cisplatin-loaded PLGA NPs prepared with W/O/W method (bar: I $\mu \mathrm{m}$ ). The blue H's represent the width of the nanoparticles. (E) TEM analysis of drugloaded NPs depicting the spherical nature of the nanocapsules (bar: $570 \mathrm{~nm}$ ). The red arrows represent a completely dark center and the blue arrows show the bright margin of the nanoparticle, indicating the loaded drug and the environmental polymer.

Abbreviations: SEM, scanning electron microscopy; TEM, transmission electron microscopy; CDDP, cis-diaminedichloroplatinum; PLGA, poly(lactic-co-glycolic acid); NPs, nanoparticles; PBS, phosphate-buffered saline; DLS, dynamic light scattering; FTIR, Fourier transform infrared spectroscopy; W/O/W, water/oil/water.

$\mathrm{IC}_{50}$ for the group that received the effective dose of cisplatin $(10 \mu \mathrm{g} / \mathrm{mL})$ were 8 and $6.5 \mu \mathrm{g} / \mathrm{mL}$, respectively. However, the survival rate of tumor cells that received $2 \mathrm{mg} / \mathrm{mL}$ of NPs was $25.42 \% \pm 3.6 \%$ for EL4 cells and $66.04 \% \pm 1.6 \%$ for SSCs.

\section{Comparison of EL4 apoptosis between free cisplatin and CDDP/PLGA NPs}

The apoptotic characteristics of the cancer cells in the group that received free cisplatin compared with the group that received NPs are shown in Figure 3. We selected random fields per sample and counted approximately 80 cells for each group. The number of TUNEL-positive EL4 cells increased to about $41.8 \pm 1.6$ with $10 \mu \mathrm{g} / \mathrm{mL}$ cisplatin treatment after 48-hour incubation. The treatment with $2 \mathrm{mg} / \mathrm{mL}$ of CDDP/ PLGA NPs significantly increased apoptosis by $45.2 \% \pm 1.2 \%$ compared to free cisplatin. These results indicated that a higher number of TUNEL-positive cells were undergoing apoptosis upon cisplatin treatment $(p \leq 0.05)$. In addition, we treated EL4 cells with $10 \mu \mathrm{g} / \mathrm{mL}$ cisplatin and $2 \mathrm{mg} / \mathrm{mL}$ 

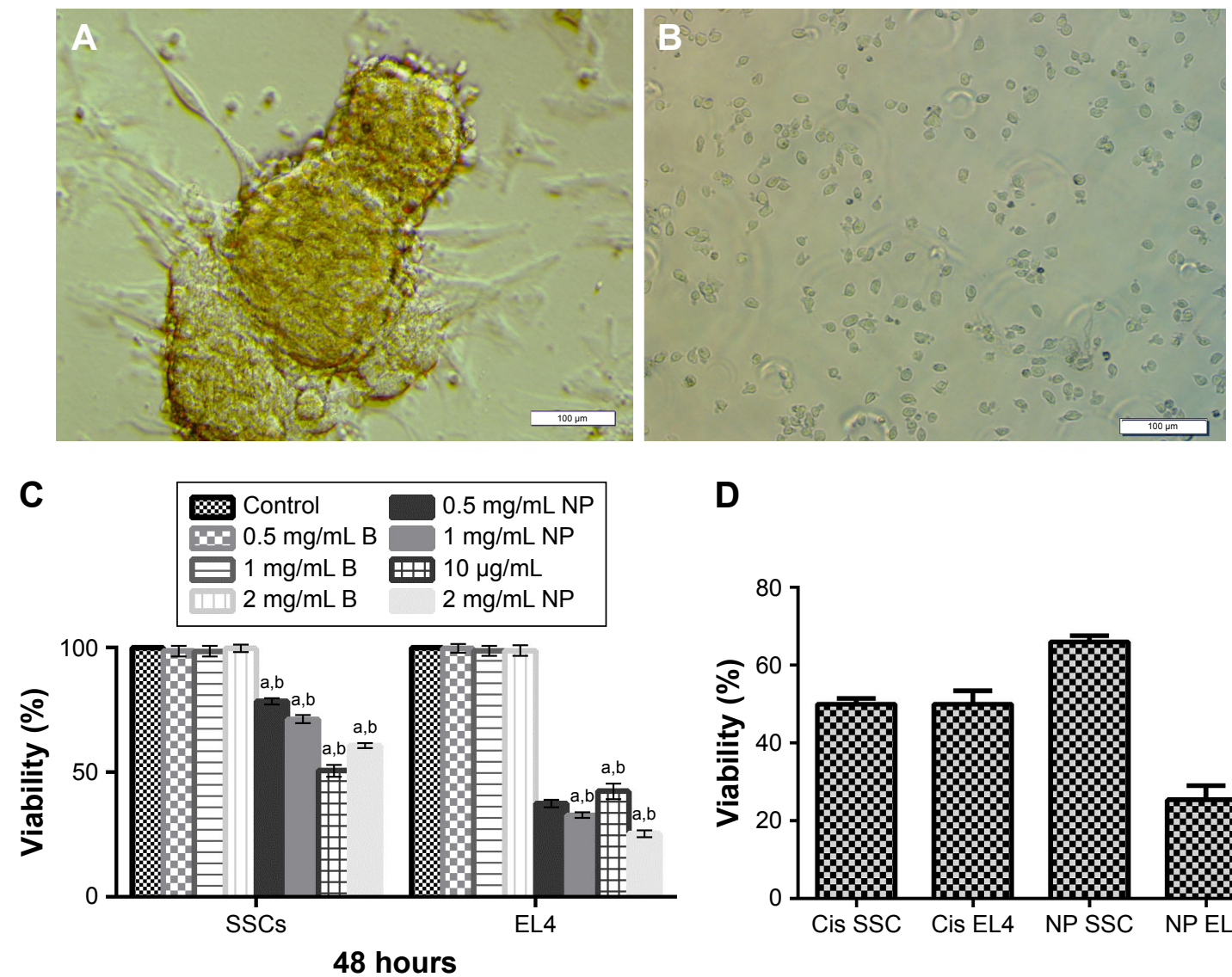

D

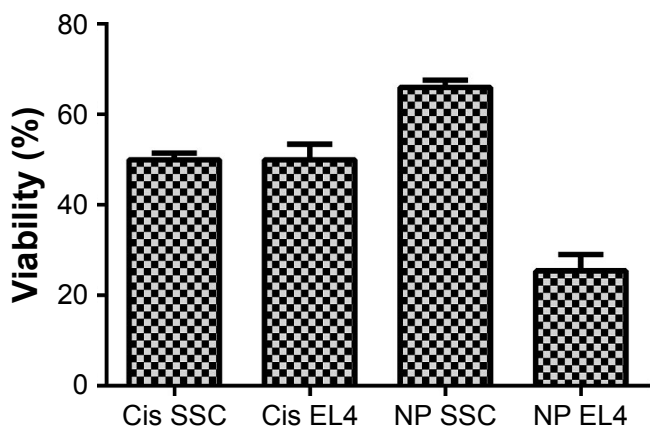

Figure 2 SSCs and EL4 cells shape and cytotoxicity analyses.

Notes: (A) A colony of SSCs $(\mathrm{bar}=100 \mu \mathrm{m})$. (B) EL4 cell line (bar $=100 \mu \mathrm{m})$. (C) Cytotoxicity study of $0.5, \mathrm{I}$, and $2 \mathrm{mg} / \mathrm{mL}$ of CDDP/PLGA and blank NPs $(0.5, \mathrm{I}$, and $2 \mathrm{mg} / \mathrm{mL})$ and $10 \mu \mathrm{g} / \mathrm{mL}$ of free cisplatin after 48-hour incubation with EL4 cells and SSCs as determined by the MTT assay (a): there is a significant difference between the experimental groups compared with the control and blank NPs group $(p \leq 0.05)$, and $(b)$ : there is a significant difference between the groups in relation to each other that received different doses of cisplatin-loaded PLGA NPs ( $p \leq 0.05$ ). (D) Comparison of $2 \mathrm{mg} / \mathrm{mL}$ concentration of CDDP/PLGA NP and free cisplatin on the cell lines. As shown by the calibration curve for the release of the drug, the results obtained are confirmed by the results of the evaluation of cell survival with MTT.

Abbreviations: SSCs, spermatogonial stem cells; CDDP, cis-diaminedichloroplatinum; PLGA, poly(lactic-co-glycolic acid); NPs, nanoparticles.

cisplatin-loaded PLGA NPs for 48 hours, and examined the apoptotic gene expression by qRT-PCR. The expression of $B A X$ and caspase- 3 was increased in the group that received NPs after 48 hours of incubation compared with that in the group that received free cisplatin (Figure $3 \mathrm{G}$ and I). The results clearly showed a significant decrease in the expression of $b c l-2$ in the cells treated with $2 \mathrm{mg} / \mathrm{mL}$ CDDP/PLGA NPs compared with that in free cisplatin group (Figure $3 \mathrm{H}$ ). The results clearly indicated an overexpression of the apoptotic gene and downregulation of antiapoptotic gene following the cisplatin treatment.

\section{Comparison SSCs and EL4 cells percentage determined by flow cytometry after treatment}

The percentage of SSCs and EL4 in the co-culture was assayed by flow cytometry after treatment. The percentage of cells that expressed CD49f (alpha-6-integrin) was on an average of $59.64 \pm 2.5$ and the percentage of cells that expressed $\mathrm{H}-2 \mathrm{~Kb}$ marker was about $0.8 \pm 0.14$ in the group that received folic acid-conjugated CDDP/PLGA NPs, whereas the percentage of SSCs and EL 4 cells was $39.43 \pm 6.33$ and $1.90 \pm 0.17$, respectively, in the group that received free cisplatin $(p \leq 0.05)$. There was no significant difference in the percentage of SSCs and EL4 cells in the group that received blank NPs compared with the control group (Figure 4).

\section{In vivo evaluation of SSCs decontamination from EL4 cells after treatment with CDDP/PLGA NPs}

As mentioned, the co-culture of SSCs and EL4 cells was injected into the seminiferous tubules of the testes after treating with CDDP/PLGA NPs. No testes or seminiferous tubules tumor was observed in the histological sections 8 weeks after transplantation. Also, we observed DiI-labeled SCC proliferation and regional colonization of stem cells (Figure 5). Furthermore, SCCs transplantation improved the condition and structure of the seminiferous tubules in 

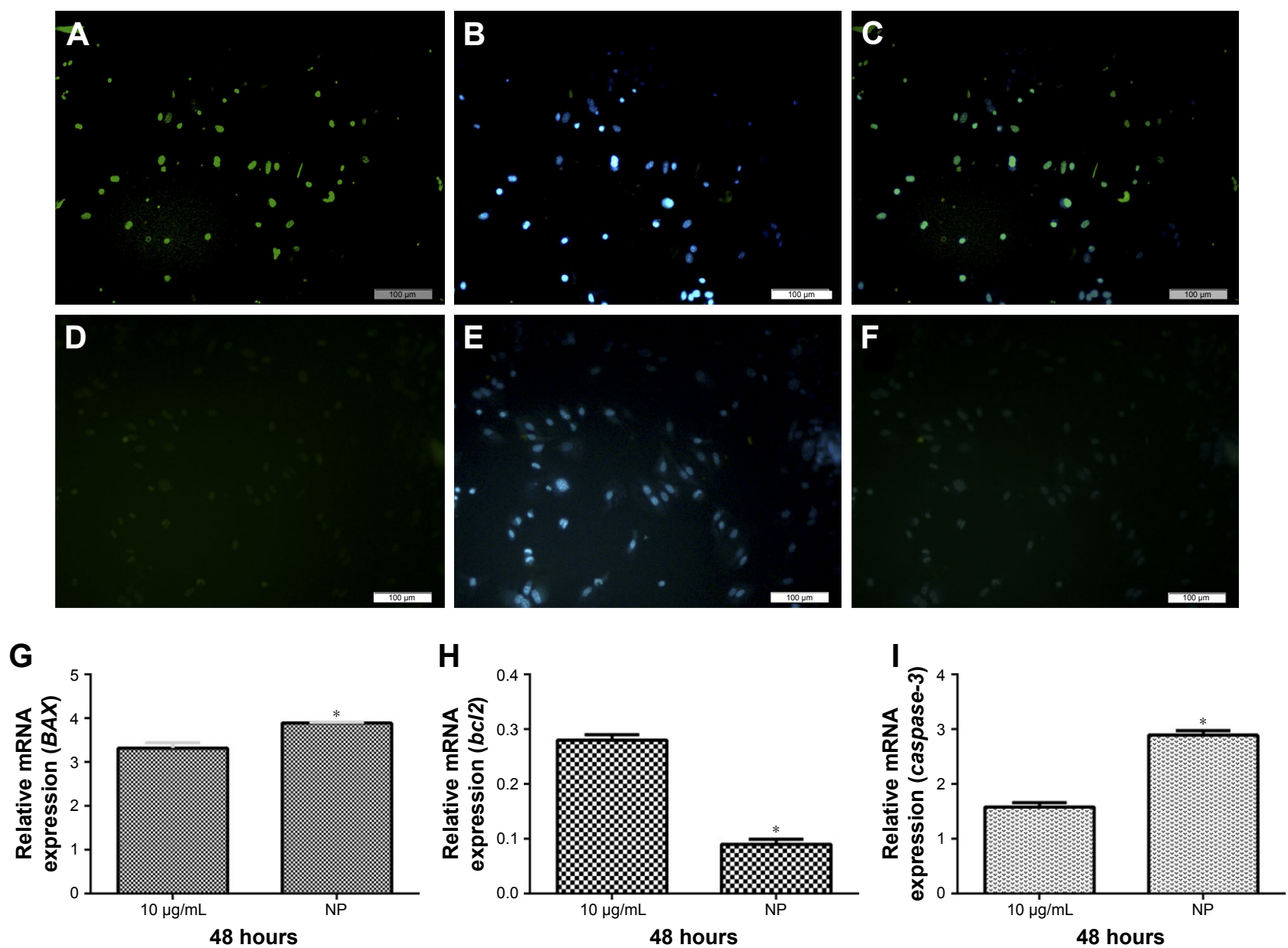

Figure 3 TUNEL assay for EL4 cells treated with free cisplatin and $2 \mathrm{mg} / \mathrm{mL}$ of CDDP/PLGA NPs and comparison of the mRNA levels of apoptosis-related genes in the EL4 cells treated with cisplatin $(10 \mu \mathrm{g} / \mathrm{mL})$ and $2 \mathrm{mg} / \mathrm{mL}$ of cisplatin-loaded PLGA NPs for 48 hours.

Notes: The green cells indicate the TUNEL-positive apoptotic cells. It can be seen that the number of apoptotic cells increased after 48 hours in the group treated with 2 mg/ mL CDDP/PLGA NPs: (A) TUNEL assay; (B) DAPI staining; and (C) merged. Comparison with free cisplatin: (D) TUNEL assay; (E) DAPI staining; and (F) merged. Activated gene expression of $(\mathbf{G})$ Bax and $(\mathbf{I})$ caspase-3. (H) Downregulation of antiapoptotic gene, bcl2. Each value represents mean \pm SD, and the experiments were carried out in triplicate. ${ }^{*} p \leq 0.05$ as compared with EL4 cells that were treated with $2 \mathrm{mg} / \mathrm{mL}$ of cisplatin-loaded PLGA NPs. Bar $=100 \mu \mathrm{m}$.

Abbreviations: CDDP, cis-diaminedichloroplatinum; PLGA, poly(lactic-co-glycolic acid); NPs, nanoparticles.

the busulfan-azoospermia model, indicating that spermatogenesis began in many seminiferous tubules.

\section{Discussion}

At present, there is no way to preserve the fertility of prepubertal cancer patients after cancer therapy. ${ }^{12,34}$ After exposure to a chemotherapeutic drug such as cisplatin, the seminiferous epithelium becomes dysfunctional due to direct damage to the germ cells and apoptosis, and thus cannot provide optimal support. ${ }^{35}$ SCC transplantation may be a hopeful method, but the possible contamination with cancerous cells is the main barrier., 9,12,36 The therapeutic efficacy of cisplatin may be limited due to its poor water solubility and high affinity of binding to plasma proteins and degradability. ${ }^{37}$ Therefore, the goal is to overcome the limitations of conventional chemotherapy, which include undesirable biodistribution, cancer cell cisplatin resistance, and severe systemic side effects. Use of NPs is promising due to their ability of targeted delivery. ${ }^{38}$

Here, we describe a novel approach for the elimination of cancerous cells from SSCs by treatment with cisplatin-loaded PLGA NPs in comparison with free cisplatin treatment. As reported above, PLGA NPs production was carried out using $\mathrm{W} / \mathrm{O} / \mathrm{W}$ double-emulsion solvent evaporation method to obtain well-rounded PLGA NPs with high encapsulation efficiency (up to $78 \%$ ). Our results showed that the burst release within the first 2 hours was similar to that observed in previous studies. ${ }^{39}$ It may be due to linking with cisplatin which just adsorbed on the outer surface of the NPs. An example showing the initial burst and linear release was also reported. ${ }^{40}$ The characteristic PLGA zeta-potential reached $2.6 \mathrm{mV}$ after surface modification by folic acid. 
A

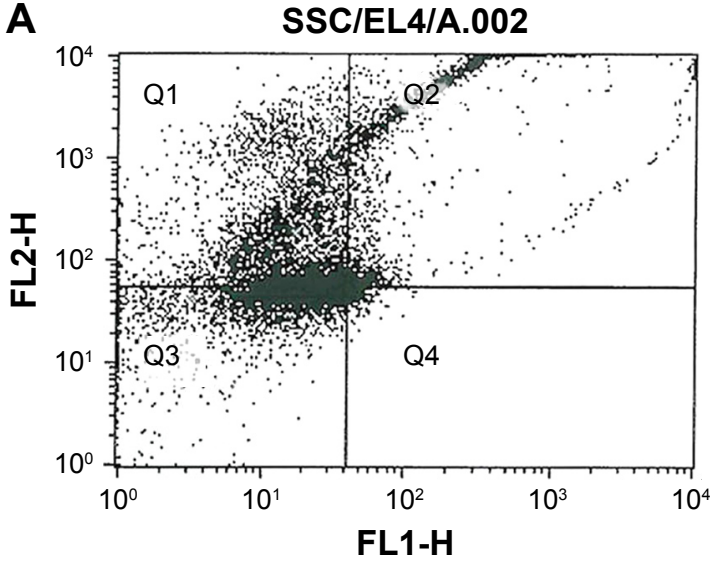

C

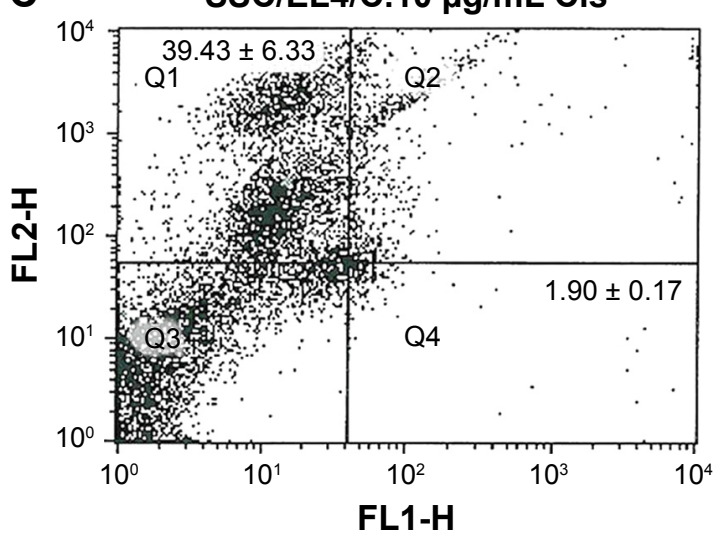

B

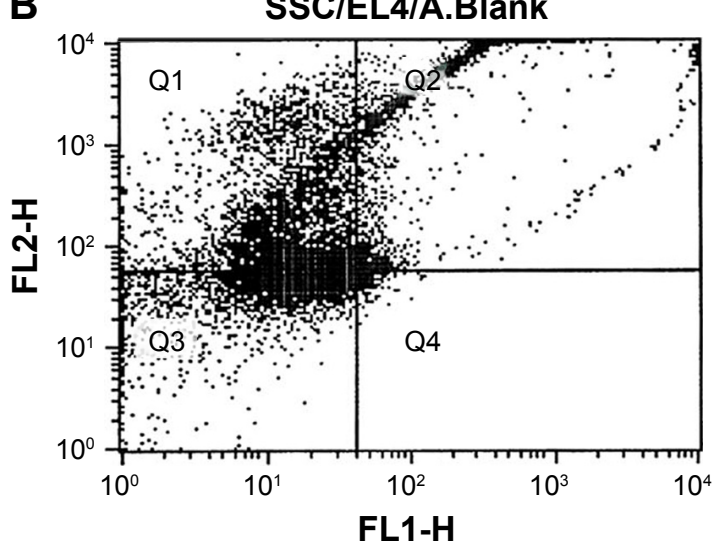

D

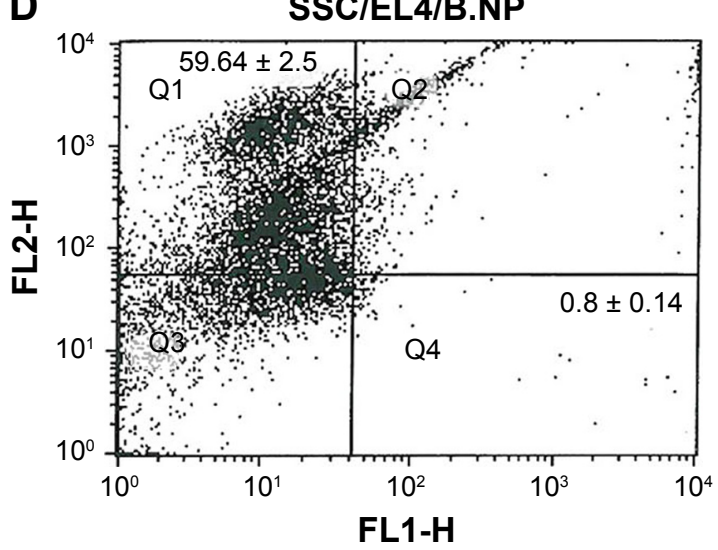

Figure 4 Flow cytometry analysis of surface markers (CD49f positive for SSCs and H-2Kb positive for EL4 cells): (A) EL4 + SSCs suspension, (B) EL4 + SSCs suspension treated with blank NPs, (C) EL4 + SSCs suspension treated with $10 \mu \mathrm{g} / \mathrm{mL}$ cisplatin, and (D) EL4 + SSCs suspension treated with $2 \mathrm{mg} / \mathrm{mL}$ cisplatin-loaded NPs.

Abbreviations: SSCs, spermatogonial stem cells; NPs, nanoparticles.

In general, cisplatin-loaded PLGA NPs have been successfully designed and spherical particles prepared, and narrow size distribution has been characterized. A sustained release of cisplatin over 4 days from folic acid-conjugated PLGA NPs in vitro was observed. The results of the characterization of cisplatin-loaded PLGA NPs supported previous investigations in which NPs were prepared using similar methods. The $\mathrm{pH}$ - or temperature-induced rapid drug release rates and thus high drug efficacy and theoretically rapid cytoplasmic drug release can be achieved if the NPs can dissolve in the acidic endosomes or lysosomes and then rapidly rupture their membranes. However, these NPs become soluble at $\mathrm{pH}$ close to 7, and thus, destabilize and release drugs in the slightly acidic extracellular spaces of solid tumors. ${ }^{41}$ But our NPs formulation did not respond to a particular stimulus and the release of drug depended on controlled polymer degradation. Actually, in our research, we determined the rate of polymer degradation and the amount of drug released at a time, and loaded a certain dose of the drug to provide a specific drug concentration for the treatment of the target cells. The results indicated that the mean size of the PLGA NPs was about $197 \mathrm{~nm}$ as determined by TEM, and the release was $62.4 \%$ at 72 hours according to the in vitro release study. Finally, no significant toxic effects were observed with empty NPs, using the equivalent amount in milligrams of loaded NPs. ${ }^{39}$

The survival rate of tumor cells treated with $2 \mathrm{mg} / \mathrm{mL}$ folic acid-conjugated CDDP/PLGA NPs after 48 hours of incubation was about $25 \%$. However, SSCs had over $60 \%$ viability compared with the tumor cell survival of approximately $50 \%$ in the group that received an effective dose of cisplatin $(10 \mu \mathrm{g} / \mathrm{mL})$. The $\mathrm{IC}_{50}$ of CDDP/PLGA NPs $(2 \mathrm{mg} / \mathrm{mL})$ was significantly higher than that observed with free cisplatin. No toxicity of blank NPs on SSCs was observed, which mimicked the findings of our previous study with a different particle. ${ }^{42}$

Due to the retention of the complex in the primary emulsion phase, cisplatin can be loaded into the NPs made of hydrophobic PLGA with hydrophilic methoxide polyethylene glycol chains. ${ }^{39}$ With the evaporation of the solvent at ambient conditions, our particles had a spherical internal 

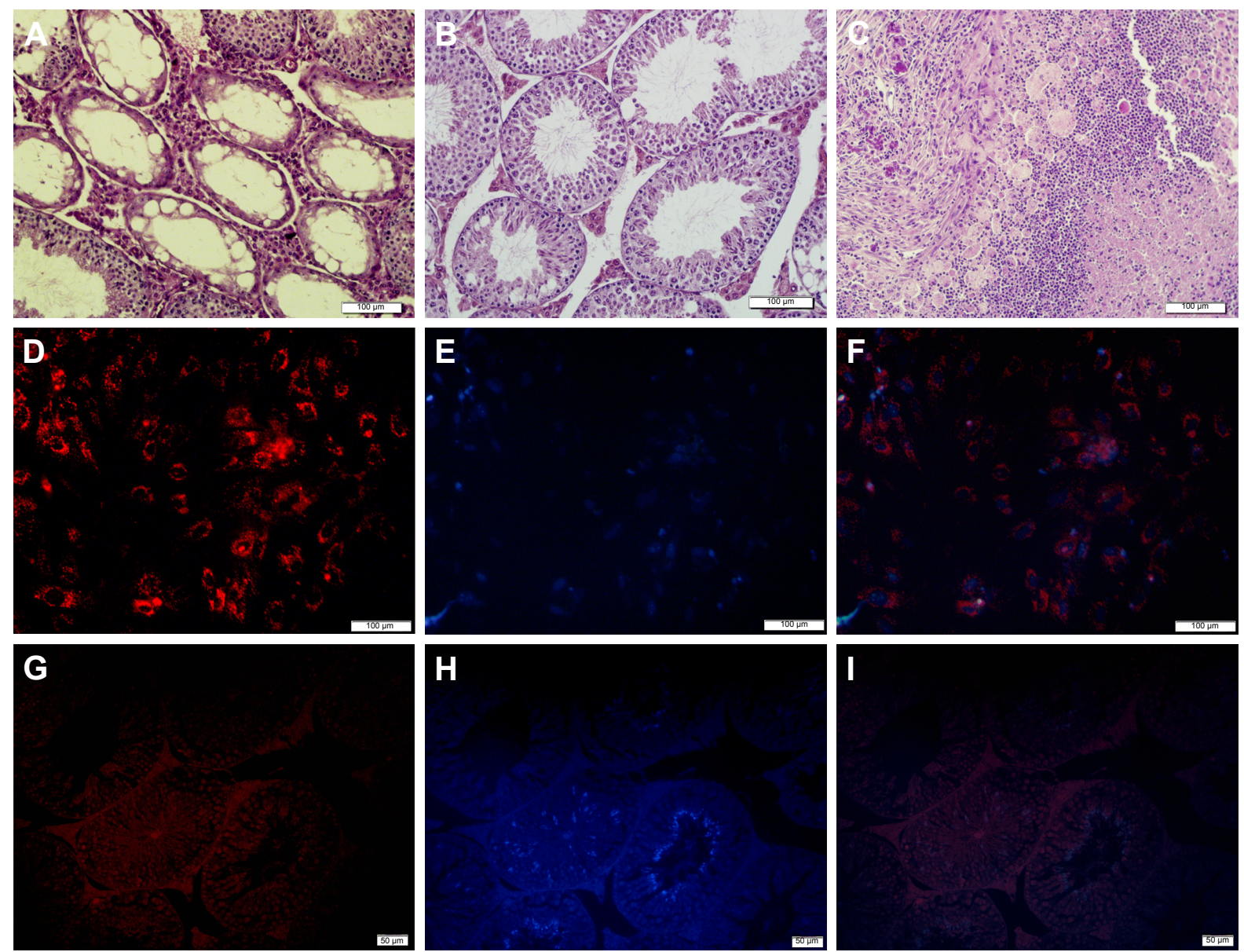

Figure 5 In vivo tumor histological examination and evaluation of decontamination of SSCs from EL4 cells after treatment with CDDP/PLGA NPs.

Notes: (A) Histological analysis of busulfan-treated control mice. (B) Normal seminiferous tubules are seen in the group that received EL4 cells and SSCs after treatment. (C) Histological section of tumor formed from EL4 cells alone stained with H\&E (bar $=100 \mu \mathrm{m}$ ). Cell labeling of SSCs and transplantation. (D) A cluster of SSCs labeled with Dil, (E) cells labeled with DAPI, and (F) merged. Bar $=100 \mu \mathrm{m}$. (G-I) Colonization and proliferation of labeled injected cells (bar $=50 \mu \mathrm{m})$.

Abbreviations: SSCs, spermatogonial stem cell; CDDP, cis-diaminedichloroplatinum; PLGA, poly(lactic-co-glycolic acid); NPs, nanoparticles.

structure. This shape seemed to be due to the persistence of cisplatin, while the shell of the particles was dark, consistent with the PLGA matrix. The results suggested that cisplatin was dispersed inside the PLGA nanocapsules. There was a difference in our findings between the sizes reported by DLS and electron microscopy. That is why, a higher hydrodynamic diameter of NPs was determined by DLS analysis compared with that detected by TEM and SEM analyses and contributed to the hydration of the surface-associated PVA. Our results demonstrated a higher fraction of apoptotic cell death in EL4 cells treated by cisplatin-loaded folic acid-conjugated PLGA NPs than that by free drug in solution. It is notable that cisplatin-entrapped NPs enhanced the apoptotic activity compared with cisplatin treatment, due to the maximum activity achieved with folic acid-conjugated NPs. The formulation also showed an enhanced therapeutic ability over free cisplatin as the NPs were targeted to the cancerous cells by folic acid in a similar way as shown in previous studies. ${ }^{32}$ A marked increase in apoptosis was found through the major effector caspase-3 by cisplatin-loaded PLGA NPs after 48 hours of incubation. Cisplatin activates apoptosis as it is a heavy metal compound and causes inhibition of DNA replication and transcription, by producing DNA cross-links. These modifications result in DNA damages that, in turn, block cell cycle causing apoptosis, finally leading to the activation of caspases cascade. ${ }^{43}$ TUNEL assay also confirmed the enhanced effectiveness of cisplatin-loaded NPs on EL4 cancerous cells. In a previous study on ovarian cancer cells, it was demonstrated that the number of TUNEL apoptotic cells in cisplatin-loaded PLGA NPs group increased compared with the ones that received cisplatin. ${ }^{37}$

Geens et al demonstrated that FACS and MACS purification is not sufficiently efficient to ensure a total depletion of malignant cells from a germ cell suspension and it induced leukemia in the recipients. ${ }^{12}$ Our results seem to contradict this promising report; however, a major problem is low efficiency of this cell-sorting technique because of low cancer cells detection. Although we were not able to entirely delete 
tumoral EL4 cells from SSCs, we did not find induced tumor in the recipients after the treatment for smart drug delivery. It appears from our results that more research on alternative decontamination techniques is necessary until the depletion of malignant cells reaches zero. Furthermore, the surface of NPs could have affected cisplatin delivery to cancerous cells while conjugated with the $\mathrm{H}-2 \mathrm{~Kb}$ antibody (anti-EL4 cells). This recent method may be utilized for targeting applications or gene delivery to induce apoptosis as a novel cancer therapy.

\section{Conclusion}

We conclude that cisplatin-loaded PLGA NPs have a significant effect on the elimination of tumoral cells from germ cells. Hence, we observed a controlled release of cisplatin from NPs as compared with free cisplatin. Our findings confirm that cisplatin-loaded NPs can serve as a novel tool for the isolation of SSCs from cancerous cells. A targeted delivery of cisplatin will improve the therapeutic efficacy of the drug and will be useful for decontamination of cancer cells. Overall, the results of this study suggest that cisplatinloaded PLGA NPs induce apoptosis in EL4 cancer cells. Also, NP-mediated cisplatin delivery may further improve the therapeutic efficacy of free cisplatin.

\section{Acknowledgments}

This work was supported by an Iran University of Medical Sciences (IUMS) grant (92-01-30-21650) and an INSF grant (92005090) for a PhD student thesis. All experiments were performed at the Cellular and Molecular Research Center (CMRC), IUMS, Tehran, Iran.

\section{Disclosure}

The authors report no conflicts of interest in this work.

\section{References}

1. Golan M, Feinshtein V, Polyak D, Scomparin A, Satchi-Fainaro R, David A. Inhibition of gene expression and cancer cell migration by CD44v3/6-targeted polyion complexes. Bioconjug Chem. 2016;27(4): 947-960.

2. Looijenga LH, Oosterhuis JW. Pathogenesis of testicular germ cell tumours. Rev Reprod. 1999;4(2):90-100.

3. Kaatsch P. Epidemiology of childhood cancer. Cancer Treat Rev. 2010;36(4):277-285

4. Wallace WH, Kelsey TW, Anderson RA. Fertility preservation in prepubertal girls with cancer: the role of ovarian tissue cryopreservation. Fertil Steril. 2016;105(1):6-12.

5. Howlader N, Noone AM, Krapcho M, et al. SEER Cancer Statistics Review, 1975-2008. Bethesda, MD: National Cancer Institute; 2011.

6. Azizollahi S, Aflatoonian R, Sadighi Gilani MA, et al. Alteration of spermatogenesis following spermatogonial stem cells transplantation in testicular torsion-detorsion mice. J Assist Reprod Genet. 2016; 33(6):771-781.
7. Koruji M, Shahverdi A, Janan A, Piryaei A, Lakpour MR, Gilani Sedighi MA. Proliferation of small number of human spermatogonial stem cells obtained from azoospermic patients. J Assist Reprod Genet. 2012;29(9):957-967.

8. Koruji M, Movahedin M, Mowla SJ, Gourabi H, Pour-Beiranvand S, Jabbari Arfaee A. Autologous transplantation of adult mice spermatogonial stem cells into gamma irradiated testes. Cell J. 2012;14(2):82-89.

9. Mirzapour T, Movahedin M, Koruji M, Nowroozi MR. Xenotransplantation assessment: morphometric study of human spermatogonial stem cells in recipient mouse testes. Andrologia. 2015;47(6):626-633.

10. Valli H, Gassei K, Orwig KE. Stem cell therapies for male infertility: where are we now and where are we going? In: Carrell DT, Schlegel PN, Racowsky C, Gianaroli L, editors. Biennial Review of Infertility. Cham: Springer; 2015:17-39.

11. Jahnukainen K, Hou M, Petersen C, Setchell B, Söder O. Intratesticular transplantation of testicular cells from leukemic rats causes transmission of leukemia. Cancer Res. 2001;61(2):706-710.

12. Geens M, Van de Velde H, De Block G, Goossens E, Van Steirteghem A, Tournaye $\mathrm{H}$. The efficiency of magnetic-activated cell sorting and fluorescence-activated cell sorting in the decontamination of testicular cell suspensions in cancer patients. Hum Reprod. 2007;22(3):733-742.

13. Dovey SL, Valli H, Hermann BP, et al. Eliminating malignant contamination from therapeutic human spermatogonial stem cells. J Clin Invest. 2013;123(4):1833-1843.

14. Hermann BP, Sukhwani M, Salati J, Sheng Y, Chu T, Orwig KE. Separating spermatogonia from cancer cells in contaminated prepubertal primate testis cell suspensions. Hum Reprod. 2011;26(12):3222-3231.

15. Valli H, Sukhwani M, Dovey SL, et al. Fluorescence- and magneticactivated cell sorting strategies to isolate and enrich human spermatogonial stem cells. Fertil Steril. 2014;102(2):566.e7-580.e7.

16. Fujita K, Ohta H, Tsujimura A, et al. Transplantation of spermatogonial stem cells isolated from leukemic mice restores fertility without inducing leukemia. J Clin Invest. 2005;115(7):1855-1861.

17. Fujita K, Tsujimura A, Miyagawa Y, et al. Isolation of germ cells from leukemia and lymphoma cells in a human in vitro model: potential clinical application for restoring human fertility after anticancer therapy. Cancer Res. 2006;66(23):11166-11171.

18. Hou M, Andersson M, Zheng C, Sundblad A, Söder O, Jahnukainen K. Decontamination of leukemic cells and enrichment of germ cells from testicular samples from rats with Roser's T-cell leukemia by flow cytometric sorting. Reproduction. 2007;134(6):767-779.

19. Valli H, Phillips BT, Shetty G, et al. Germline stem cells: toward the regeneration of spermatogenesis. Fertil Steril. 2014;101(1):3-13.

20. Kartalou M, Essigmann JM. Recognition of cisplatin adducts by cellular proteins. Mutat Res. 2001;478(1-2):1-21

21. Madias NE, Harrington JT. Platinum nephrotoxicity. Am J Med. 1978; 65(2):307-314.

22. Prabhu RH, Patravale VB, Joshi MD. Polymeric nanoparticles for targeted treatment in oncology: current insights. Int J Nanomedicine. 2015;10:1001-1018.

23. Shabani R, Ashtari K, Behnam B, et al. In vitro toxicity assay of cisplatin on mouse acute lymphoblastic leukaemia and spermatogonial stem cells. Andrologia. 2016;48(5):584-594.

24. Haley B, Frenkel E. Nanoparticles for drug delivery in cancer treatment. Urol Oncol. 2008;26(1):57-64.

25. Acharya S, Sahoo SK. PLGA nanoparticles containing various anticancer agents and tumour delivery by EPR effect. Adv Drug Deliv Rev. 2011;63(3):170-183.

26. Sadat Tabatabaei Mirakabad F, Nejati-Koshki K, Akbarzadeh A, et al. PLGA-based nanoparticles as cancer drug delivery systems. Asian Pac J Cancer Prev. 2014;15(2):517-535.

27. Pérez-Herrero E, Fernández-Medarde A. Advanced targeted therapies in cancer: drug nanocarriers, the future of chemotherapy. Eur J Pharm Biopharm. 2015;93:52-79.

28. Low PS, Kularatne SA. Folate-targeted therapeutic and imaging agents for cancer. Curr Opin Chem Biol. 2009;13(3):256-262.

29. Sudimack J, Lee RJ. Targeted drug delivery via the folate receptor. Adv Drug Deliv Rev. 2000;41(2):147-162. 
30. Low PS, Antony AC. Folate receptor-targeted drugs for cancer and inflammatory diseases. Adv Drug Deliv Rev. 2004;56(8):1055-1058.

31. Ashjari M, Khoee S, Mahdavian AR. Controlling the morphology and surface property of magnetic/cisplatin-loaded nanocapsules via W/O/W double emulsion method. Colloids Surf A Physicochem Eng Asp. 2012;408:87-96.

32. Das M, Sahoo SK. Folate decorated dual drug loaded nanoparticle: role of curcumin in enhancing therapeutic potential of nutlin-3a by reversing multidrug resistance. PLoS One. 2012;7(3):e32920.

33. Ogawa T, Aréchaga JM, Avarbock MR, Brinster RL. Transplantation of testis germinal cells into mouse seminiferous tubules. Int J Dev Biol. 1997;41(1):111-122.

34. Aliakbari F, Gilani MA, Amidi F, et al. Improving the Efficacy of Cryopreservation of Spermatogonia Stem Cells by Antioxidant Supplements. Cellular Reprogramming. 2016;18(2):87-95.

35. Marcon L, Zhang X, Hales BF, Robaire B, Nagano MC. Effects of chemotherapeutic agents for testicular cancer on rat spermatogonial stem/progenitor cells. J Androl. 2011;32(4):432-443.

36. Shams A, Eslahi N, Movahedin M, Izadyar F, Asgari H, Koruji M. Future of spermatogonial stem cell culture: application of nanofiber scaffolds. Curr Stem Cell Res Ther. 2017;12(7):544-553.
37. Cheng L, Jin C, Lv W, Ding Q, Han X. Developing a highly stable PLGA-mPEG nanoparticle loaded with cisplatin for chemotherapy of ovarian cancer. PLoS One. 2011;6(9):e25433.

38. De Jong WH, Borm PJ. Drug delivery and nanoparticles: applications and hazards. Int J Nanomedicine. 2008;3(2):133-149.

39. Menale C, Piccolo MT, Favicchia I, et al. Efficacy of piroxicam plus cisplatin-loaded PLGA nanoparticles in inducing apoptosis in mesothelioma cells. Pharm Res. 2015;32(2):362-374.

40. Yang YY, Chung TS, Bai XL, Chan WK. Effect of preparation conditions on morphology and release profiles of biodegradable polymeric microspheres containing protein fabricated by double-emulsion method. Chem Eng Sci. 2000;55(12):2223-2236.

41. Xu P, Van Kirk EA, Murdoch WJ, et al. Anticancer efficacies of cisplatin-releasing $\mathrm{pH}$-responsive nanoparticles. Biomacromolecules. 2006;7(3):829-835.

42. Ashjari M, Dehfuly S, Fatehi D, Shabani R, Koruji M. Efficient functionalization of gold nanoparticles using cysteine conjugated protoporphyrin IX for singlet oxygen production in vitro. RSC Adv. 2015;5(127): 104621-104628.

43. Wang D, Lippard SJ. Cellular processing of platinum anticancer drugs. Nat Rev Drug Discov. 2005;4(4):307-320.
International Journal of Nanomedicine

\section{Publish your work in this journal}

The International Journal of Nanomedicine is an international, peerreviewed journal focusing on the application of nanotechnology in diagnostics, therapeutics, and drug delivery systems throughout the biomedical field. This journal is indexed on PubMed Central,

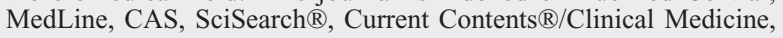

\section{Dovepress}

Journal Citation Reports/Science Edition, EMBase, Scopus and the Elsevier Bibliographic databases. The manuscript management system is completely online and includes a very quick and fair peer-review system, which is all easy to use. Visit http://www.dovepress.com/ testimonials.php to read real quotes from published authors. 